\section{(2) OPEN ACCESS}

\title{
Development and validation of a prediction model for 30-day mortality in hospitalised patients with COVID-19: the COVID-19 SEIMC score
}

\author{
Juan Berenguer (1) , ${ }^{1}$ Alberto M Borobia, ${ }^{2}$ Pablo Ryan, ${ }^{3}$ Jesús Rodríguez-Baño, ${ }^{4}$ \\ Jose M Bellón, ${ }^{5}$ Inmaculada Jarrín, ${ }^{6}$ Jordi Carratalà, Jerónimo Pachón, ${ }^{8}$ \\ Antonio J Carcas, ${ }^{2}$ María Yllescas, ${ }^{9}$ José R Arribas, ${ }^{10}$ COVID-19@Spain and COVID@ \\ HULP Study Groups
}

\begin{abstract}
- Additional material is published online only. To view, please visit the journal online (http://dx.doi.org/10.1136/ thoraxjnl-2020-216001).
\end{abstract}

For numbered affiliations see end of article.

\section{Correspondence to}

Dr Juan Berenguer, Infectious Diseases, Hospital General Universitario Gregorio Marañón, Madrid 28007, Spain; jbb4@me.com

Received 14 August 2020 Revised 11 January 2021 Accepted 1 February 2021 Published Online First 25 February 2021

\section{Check for updates}

(C) Author(s) (or their employer(s)) 2021. Re-use permitted under CC BY-NC. No commercial re-use. See rights and permissions. Published by BMJ.

To cite: Berenguer J, Borobia AM, Ryan P, et al.

Thorax 2021;76:920-929.

\begin{abstract}
Objective To develop and validate a prediction model of mortality in patients with COVID-19 attending hospital emergency rooms.

Design Multivariable prognostic prediction model.

Setting 127 Spanish hospitals.

Participants Derivation (DC) and external validation (VC) cohorts were obtained from multicentre and singlecentre databases, including 4035 and 2126 patients with confirmed COVID-19, respectively.

Interventions Prognostic variables were identified using multivariable logistic regression.

Main outcome measures 30-day mortality.

Results Patients' characteristics in the DC and VC were median age 70 and 61 years, male sex $61.0 \%$ and $47.9 \%$, median time from onset of symptoms to admission 5 and 8 days, and 30-day mortality 26.6\% and $15.5 \%$, respectively. Age, low age-adjusted saturation of oxygen, neutrophil-to-lymphocyte ratio, estimated glomerular filtration rate by the Chronic Kidney Disease Epidemiology Collaboration (CKDEPI) equation, dyspnoea and sex were the strongest predictors of mortality. Calibration and discrimination were satisfactory with an area under the receiver operating characteristic curve with a $95 \% \mathrm{Cl}$ for prediction of 30-day mortality of $0.822(0.806-0.837)$ in

\section{Key messages}

What is the key question?

- The development of a predictive prognostic model is essential for improving the management of patients with severe COVID-19.

What is the bottom line?

- In a recent systematic review and critical appraisal of prediction models for COVID-19, 50 prognostic models were identified. All models were considered to have a high risk of bias, and none were recommended for clinical use.

Why read on?

- The COVID-19 SEIMC score was developed and externally validated with two large datasets from patients hospitalised with laboratoryconfirmed COVID-19. The score based on age, low age-adjusted saturation of oxygen, neutrophil-to-lymphocyte ratio, estimated glomerular filtration rate by the CKD-EPI equation, dyspnoea and sex could identify the probability of 30-day mortality with a high degree of accuracy among patients with COVID-19.
\end{abstract} the DC and $0.845(0.819-0.870)$ in the VC. A simplified score system ranging from 0 to 30 to predict 30-day mortality was also developed. The risk was considered to be low with $0-2$ points $(0 \%-2.1 \%)$, moderate with $3-5$ $(4.7 \%-6.3 \%)$, high with $6-8(10.6 \%-19.5 \%)$ and very high with 9-30 $(27.7 \%-100 \%)$.

Conclusions A simple prediction score, based on readily available clinical and laboratory data, provides a useful tool to predict 30-day mortality probability with a high degree of accuracy among hospitalised patients with COVID-19.

\section{INTRODUCTION}

The clinical spectrum of the novel SARS-CoV-2 associated COVID-19 varies broadly, from asymptomatic disease to pneumonia and life-threatening complications, including acute respiratory distress syndrome, multisystem organ failure and death. ${ }^{1-4}$

The main poor prognostic factor identified in different series of COVID-19 is advanced age. ${ }^{356}$
Other factors that have been associated with poor outcomes include male gender, several comorbidities, lymphocyte counts, high concentrations of different inflammatory or coagulation markers, serum levels of different cytokines and features derived from imaging studies. ${ }^{5-10}$

Prediction prognostic models are developed to aid healthcare providers in estimating the probability or risk that a specific event will occur, to inform their decision-making. ${ }^{11}$ Prediction models can be based on regression or machine learning. ${ }^{12}$ In a recent systematic review and critical appraisal of prediction models for diagnosis and prognosis of COVID-19, 50 prognostic models were identified; 23 estimated mortality risk, 8 aimed to predict severe disease or critical illness and the remaining 19 assessed other outcomes. ${ }^{13}$ The majority of the models included in the review used clinical and laboratory data from Chinese patients. All models were considered to have a high risk of bias due 
Table 1 Comparison of participant characteristics in the derivation and external validation cohorts

\begin{tabular}{|c|c|c|c|c|c|c|c|}
\hline \multirow[b]{2}{*}{ Characteristic } & \multicolumn{3}{|c|}{$\begin{array}{l}\text { Derivation cohort } \\
(\mathrm{N}=4035)\end{array}$} & \multicolumn{3}{|c|}{$\begin{array}{l}\text { External validation cohort } \\
(\mathrm{N}=2202)\end{array}$} & \multirow[b]{2}{*}{$P$ value } \\
\hline & Missing values & Valid cases & Value & Missing values & Valid cases & Value & \\
\hline \multicolumn{8}{|l|}{ Demographics } \\
\hline Median age (IQR)—years & 4 & 4031 & $70(56-80)$ & 0 & 2202 & $61(46-78)$ & $<0.001$ \\
\hline Male sex-N (\%) & 48 & 3987 & $2433(61.0)$ & 1 & 2201 & $1054(47.9))$ & $<0.001$ \\
\hline \multicolumn{8}{|l|}{ Comorbidity } \\
\hline Current smoker-N (\%) & 1.118 & 2917 & $197(6.8)$ & 97 & 2105 & $156(7.4)$ & $<0.001$ \\
\hline Hypertension-N (\%) & 25 & 4010 & $2052(51.2)$ & 17 & 2185 & $907(41.5)$ & $<0.001$ \\
\hline Diabetes—N (\%) & 33 & 4002 & $871(21.8)$ & 16 & 2186 & $378(17.3)$ & $<0.001$ \\
\hline Chronic kidney disease $-\mathrm{N}(\%)$ & 35 & 4000 & $199(5.0)$ & 2039 & 163 & $76(46.6)$ & $<0.001$ \\
\hline Obesity (BMI>30)—N (\%) & 429 & 3606 & $497(13.8)$ & 61 & 2141 & $233(10.9)$ & 0.001 \\
\hline Chronic inflammatory disease $-\mathrm{N}(\%)$ & 38 & 3997 & $231(5.8)$ & 0 & 2202 & $255(11.6)$ & $<0.001$ \\
\hline HIVIAIDS-N (\%) & 73 & 3962 & $26(0.7)$ & 20 & 2182 & $13(0.6)$ & $<0.001$ \\
\hline \multicolumn{8}{|l|}{ Disease chronology } \\
\hline $\begin{array}{l}\Delta \mathrm{t} \text { onset of symptoms to admission, days- } \\
\text { median (IQR) }\end{array}$ & 462 & 3573 & $5(2-7)$ & 939 & 1263 & $8(5-11)$ & $<0.001$ \\
\hline Symptoms and signs & & & & & & & $<0.001$ \\
\hline History of fever-N (\%) & 35 & 4000 & $3240(81.0)$ & 35 & 2167 & $1568(72.4)$ & $<0.001$ \\
\hline Cough-N (\%) & 51 & 3984 & $2862(71.8)$ & 36 & 2166 & $1098(50.7)$ & $<0.001$ \\
\hline Malaise-N (\%) & 121 & 3914 & $2505(64.0)$ & 38 & 2164 & $907(41.9)$ & $<0.001$ \\
\hline Dyspnoea-N (\%) & 55 & 3980 & $1953(49.1)$ & 37 & 2165 & $1098(50.7)$ & $<0.001$ \\
\hline Myalgia/Arthralgia-N (\%) & 226 & 3809 & $947(24,9)$ & & 2160 & $588(27.2)$ & 0.045 \\
\hline Sputum production—N (\%) & 72 & 3963 & $956(24.1)$ & 61 & 2141 & $311(14.5)$ & $<0.001$ \\
\hline Vomiting/Nausea-N (\%) & 111 & 3924 & $488(12.4)$ & 0 & 2202 & $295(13.4)$ & $<0.001$ \\
\hline Diarrhoea—N (\%) & 123 & 3912 & $471(12.0)$ & 37 & 2165 & $482(22.3)$ & $<0.001$ \\
\hline \multicolumn{8}{|l|}{ Radiology } \\
\hline Lung infiltrates on admission $-\mathrm{N}(\%)$ & 165 & 3870 & $3002(77.6)$ & 8 & 2194 & $1559(71,1)$ & $<0.001$ \\
\hline \multicolumn{8}{|l|}{ Oxygenation } \\
\hline Age adjusted low $\mathrm{SaO}_{2}-\mathrm{N}(\%)$ & 490 & 3545 & $942(26.6)$ & 423 & 1779 & $344(19.3)$ & $<0.001$ \\
\hline \multicolumn{8}{|l|}{ Laboratory parameter } \\
\hline Neutrophil-to-lymphocyte ratio-Median (IQR) & 90 & 3945 & $4.5(2.7-7.7)$ & 636 & 1566 & $4.7(2.9-8.0)$ & 0.013 \\
\hline Platelets—number $\times 10^{12} \mathrm{~L}$-Median (IQR) & 75 & 3960 & $178(139-226)$ & 636 & 1566 & $218(169-285)$ & $<0.001$ \\
\hline D-dimer—ng/mL—Median (IQR) & 2472 & 1563 & $580(339-1040)$ & 1325 & 877 & $736(418-1374)$ & $<0.001$ \\
\hline eGFR—mL/min/1.73 $\mathrm{m}^{2}$ (CKD-EPI)—Median (IQR) & 140 & 3895 & $78.4(56.5-93.6)$ & 645 & 1557 & $88.9(71.5-103.1)$ & $<0.001$ \\
\hline ALT—U/L—Median (IQR) & 796 & 3239 & $26(18-41)$ & 719 & 1483 & $31(20-48)$ & $<0.001$ \\
\hline Serum albumin—g/dL—Median (IQR) & 2624 & 1411 & $3.5(3.2-3.9)$ & 1071 & 1131 & $4.3(3.9-4.5)$ & $<0.001$ \\
\hline Lactate dehydrogenase-U/L—Median (IQR) & 1457 & 2578 & $290(224-403)$ & 967 & 1235 & $320(254-404)$ & $<0.001$ \\
\hline C reactive protein—mg/L—Median (IQR) & 358 & 3677 & $54(20-116)$ & 782 & 1420 & $75(25-151)$ & $<0.001$ \\
\hline
\end{tabular}

ALT, alanine aminotransferase; BMI, body mass index; eGFR, estimated glomerular filtration rate; Sa02, saturation of oxygen; $\Delta \mathrm{t}$, time interval.

to a combination of poor reporting and poor methodological conduct for participant selection, predictor description and statistical methods, and none were recommended for clinical use. ${ }^{1314}$ Eight additional studies of prognostic prediction models for COVID-19, including predominantly participants from China, have been published. ${ }^{15-22}$ Outcomes included mortality in five studies ${ }^{16}{ }^{19-21}$ and severe disease or critical illness in three. ${ }^{151822}$ The model performance was good across all studies, although the same methodological limitations found in the metaanalysis also applied.

The development of a high-quality clinical predictive model of death to stratify patients into risk groups is essential for improving the management of patients with severe COVID-19 and evaluating therapeutic interventions' efficacy. Our study's objective was to develop and validate a prediction score to estimate the probability of 30-day mortality in patients with severe COVID-19.

\section{METHODS}

The predictive model's development followed the recommendations stated in the Transparent Reporting of a multivariable prediction model for Individual Prognosis or Diagnosis (TRIPOD) Initiative ${ }^{1123}$ (see online supplemental appendix table $1)$. 
Table 2 Unadjusted association between candidate predictor variables and outcome in the derivation cohort ( $\mathrm{N}=4035)$

\begin{tabular}{|c|c|c|c|c|c|}
\hline \multirow[b]{2}{*}{ Characteristic } & \multirow[b]{2}{*}{ Number/with data (\%) } & \multicolumn{2}{|c|}{ Death by day 30} & \multirow{2}{*}{$\begin{array}{l}\text { OR } \\
(95 \% \mathrm{Cl})\end{array}$} & \multirow[b]{2}{*}{$P$ value } \\
\hline & & Yes & No & & \\
\hline Sex & & & & & $<0.001$ \\
\hline Female & $1554 / 3987$ & 341 & 1213 & 1 & \\
\hline Male & $2433 / 3987$ & 721 & 1712 & 1.5 (1.29 to 1.74$)$ & \\
\hline Age (years) & & & & & $<0.001$ \\
\hline$<=40$ & $302 / 4031(7.5)$ & 9 & 293 & 1 & \\
\hline $40-49$ & $374 / 4031(9.3)$ & 16 & 358 & 1.45 (0.63 to 3.34$)$ & \\
\hline $50-54$ & $266 / 4031(6.6)$ & 19 & 247 & 2.50 (1.11 to 5.63$)$ & \\
\hline $55-59$ & 279/4031 (6.9) & 38 & 241 & 5.13 (2.43 to 10.8$)$ & \\
\hline $60-64$ & $356 / 4031(8.8)$ & 53 & 303 & 5.69 (2.76 to 11.7$)$ & \\
\hline $65-69$ & 401/4031 (9.9) & 78 & 323 & 7.86 (3.87 to 15.0$)$ & \\
\hline $70-74$ & $522 / 4031(12.9)$ & 123 & 399 & 10.0 (5.02 to 20.1$)$ & \\
\hline $75-79$ & $521 / 4031(12.9)$ & 201 & 320 & 20.4 (10.3 to 40.6$)$ & \\
\hline $80-84$ & $410 / 4031(10.2)$ & 196 & 214 & 29.8 (14.9 to 59.5$)$ & \\
\hline $85-89$ & $379 / 4031$ (9.4) & 200 & 179 & 36.4 (18.3 to 72.8$)$ & \\
\hline$>=90$ & $221 / 4031$ (5.5) & 140 & 81 & 56.3 (27.5 to 115$)$ & \\
\hline Hypertension & $2052 / 4010(51.2)$ & 764 & 1288 & 3.22 (2.76 to 3.74 ) & $<0.001$ \\
\hline Obesity & 497/3606 (13.8) & 169 & 328 & 1.57 (1.29 to 1.93$)$ & $<0.001$ \\
\hline Liver cirrhosis & $54 / 3998(1.4)$ & 23 & 31 & 2.08 (1.21 to 3.58 ) & 0.008 \\
\hline Chronic neurological disorder & $373 / 4002(9.3)$ & 161 & 212 & 2.31 (1.85 to 2.87 ) & $<0.001$ \\
\hline Neoplasm (active) & $352 / 4035(8.7)$ & 152 & 200 & 2.28 (1.82 to 2.85$)$ & $<0.001$ \\
\hline Dementia & $315 / 3979(7.9)$ & 184 & 131 & 4.52 (3.57 to 5.73$)$ & $<0.001$ \\
\hline Myalgia/Arthralgia & $947 / 3809(24.9)$ & 155 & 792 & 0.49 (0.40 to 0.59$)$ & $<0.001$ \\
\hline Cough & 2862/3984 (71.8) & 688 & 2174 & 0.68 (0.59 to 0.79$)$ & $<0.001$ \\
\hline Dyspnoea & $1953 / 3980(49.1)$ & 668 & 1285 & 2.19 (1.89 to 2.53$)$ & $<0.001$ \\
\hline Altered consciousness & 450/3931 (11.4) & 220 & 230 & 3.15 (2.58 to 3.86$)$ & $<0.001$ \\
\hline White cell count-cells $/ \times 10^{9} / \mathrm{L}$ & & & & & $<0.001$ \\
\hline$<=4000$ & $666 / 3971$ & 132 & 534 & 1 & \\
\hline $4000-12000$ & 2993/3971 & 778 & 2215 & $1.42(1.15$ to 1.75$)$ & \\
\hline$>12000$ & $312 / 3971$ & 151 & 161 & 3.79 (2.83 to 5.08$)$ & \\
\hline Neutrophil-to-lymphocyte ratio & & & & & $<0.001$ \\
\hline$<3.22$ & $1316 / 3945$ & 207 & 1109 & 1 & \\
\hline $3.22-6.33$ & $1314 / 3945$ & 298 & 1016 & 1.57 (1.29 to 1.91$)$ & \\
\hline$>6.33$ & $1315 / 3945$ & 547 & 768 & 3.82 (3.17 to 4.59$)$ & \\
\hline eGFR—-mL/min/1.73 m² (CKD-EPI) & & & & & $<0.001$ \\
\hline$>=60$ & 2786/3895 (71.5) & 512 & 2274 & 1 & \\
\hline $30-59$ & $844 / 3895(21.7)$ & 379 & 465 & 3.62 (3.07 to 4.27 ) & \\
\hline$<30$ & $265 / 3895(6.8)$ & 153 & 112 & 6.07 (4.67 to 7.88$)$ & \\
\hline Low $\mathrm{SaO}_{2}$ (age-adjusted)* & $942 / 3545(26.6)$ & 413 & 529 & 3.44 (2.93 to 4.05$)$ & $<0.001$ \\
\hline INR $>1.1$ & $1503 / 3301(45.5)$ & 524 & 979 & 2.20 (1.88 to 2.57$)$ & $<0.001$ \\
\hline $\mathrm{CRP}>5 \mu \mathrm{g} / \mathrm{L}$ & $3378 / 3677$ & 939 & 2439 & 3.21 (2.21 to 4.67 ) & $<0.001$ \\
\hline
\end{tabular}

${ }^{*} \leq 90 \%$ for patients aged $>50$ years and $\leq 93 \%$ for patients aged $\leq 50$ years.

CKD-EPI, Chronic Kidney Disease Epidemiology Collaboration equation; CRP, C reactive protein; INR, international normalised ratio; SaO2, saturation of oxygen.

\section{Source of data}

The data source was the databases of two large retrospective cohorts of hospitalised patients with COVID-19 in Spain in 2020. The derivation cohort (DC) was the COVID-19@Spain, a multicentre cohort of patients hospitalised from 2 February to 17 March, with 17 April as the follow-up censoring date, sponsored by the Spanish Society of Infectious Diseases and Clinical
Microbiology (SEIMC), and registered in ClinicalTrials.gov (NCT04355871). ${ }^{24}$ The external validation was COVID-19@ HULP, a large single-centre cohort of patients admitted to La Paz University Hospital in Madrid (Spain) from 25 February (the first case admitted) to 19 April; and registered in the European Union Electronic Register of Post-Authorisation Studies (EUPAS34331). ${ }^{25}$ 
Table 3 Predictive model for 30-day mortality at presentation in hospitalised patients with COVID-19

\begin{tabular}{|c|c|c|c|c|}
\hline Predictor variable & Coefficient & SE & OR $(95 \% \mathrm{Cl})$ & $p>z$ \\
\hline Age & & & & $<0.001$ \\
\hline 40-49 years & 0.082 & 0.446 & 1.09 (0.45 to 2.6$)$ & \\
\hline $55-59$ years & 1.058 & 0.412 & 2.88 (1.28 to 6.46$)$ & \\
\hline $60-64$ years & 1.228 & 0.394 & 3.42 (1.58 to 7.4$)$ & \\
\hline $75-79$ years & 2.268 & 0.373 & 9.66 (4.65 to 20.07 ) & \\
\hline $80-84$ years & 2.695 & 0.377 & $14.8(7.08$ to 30.96$)$ & \\
\hline $85-89$ years & 2.803 & 0.379 & 16.49 (7.84 to 34.67$)$ & \\
\hline$\geq 90$ years & 3.103 & 0.397 & 22.26 (10.22 to 48.48$)$ & \\
\hline$>6.33$ & 0.657 & 0.119 & 1.93 (1.53 to 2.44$)$ & \\
\hline eGFR (CKD-EPI) & & & & $<0.001$ \\
\hline $30-59 \mathrm{~mL} / \mathrm{min} / 1.73 \mathrm{~m}^{2}$ & 0.498 & 0.109 & 1.65 (1.33 to 2.04$)$ & \\
\hline$<30 \mathrm{~mL} / \mathrm{min} / 1.73 \mathrm{~m}^{2}$ & 1.093 & 0.176 & 2.98 (2.11 to 4.21$)$ & \\
\hline Dyspnoea & 0.414 & 0.097 & 1.51 (1.25 to 1.83$)$ & $<0.001$ \\
\hline Male sex & 0.466 & 0.098 & 1.59 (1.31 to 1.93$)$ & $<0.001$ \\
\hline Intercept & -4.266 & 0.360 & & \\
\hline
\end{tabular}

CKD-PI, Chronic Kidney Disease Epidemiology Collaboration equation; eGFR, estimated glomerular filtration rate calculated by the CKD-EPI; SaO2, oxygen saturation.

\section{Participants}

The DC included the first consecutive 4035 patients with COVID-19 admitted to 127 hospitals distributed across all regions in Spain. The external validation cohort (VC) included

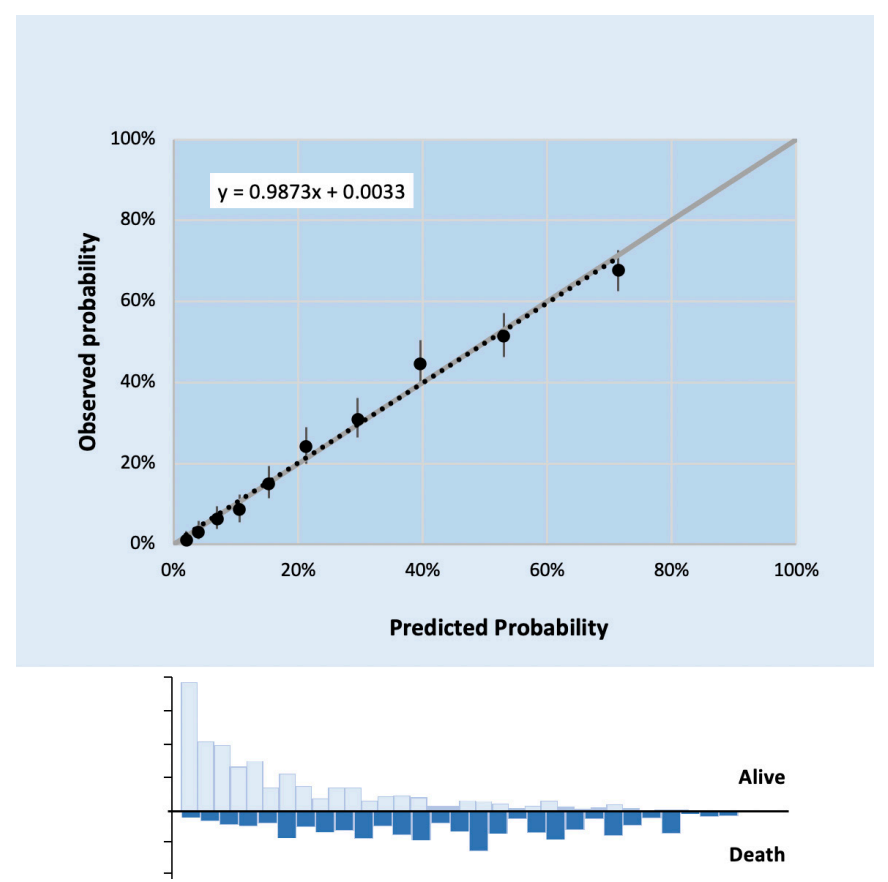

Figure 1 Calibration of the final prognostic model in the derivation cohort. Observed versus predicted risk of 30-day mortality, with estimates of the calibration slope and intercept (Hosmer-Lemeshow test $=11.21, p=0.1902$ vs $p<0.05)$.
2126 of the 2226 patients from COVID-19@HULP after the exclusion of the 100 patients contributing to COVID-19@ Spain. The eligibility criteria in the DC and external VC were hospital admission due to COVID-19 confirmed with real-time PCR for SARS-CoV-2. No age limit was required in the DC, whereas an age of 18 years or older was an eligibility criterion in the external VC. The DC and VC were identical in terms of setting and definitions for outcomes and predictors. Besides, data in both cohorts were collected using the same modified version of the case report form (CRF) of the WHO-International Severe Acute Respiratory and Emerging Infections Consortium (ISARIC) Core CRF. ${ }^{26}$

\section{Outcome}

The outcome was 30-day all-cause mortality, measured from the day of hospital admission. Patients that were discharged alive before 30 days after admission were assumed to have survived for at least 30 days.

\section{Predictors}

Predictors were preselected among the 17 baseline variables, recorded at hospital admission, independently associated with death in the COVID-19@Spain cohort by multivariable Cox regression analyses. ${ }^{24}$ These variables were distributed in the following five clusters: (1) demographics, age in years and sex at birth; (2) comorbidities defined as diagnoses included in the medical record such as hypertension, obesity (body mass index $>30$ ), liver cirrhosis, chronic neurological disorder, active neoplasia (solid or haematologic) and dementia; (3) signs or symptoms, including dyspnoea and confusion; (4) low ageadjusted capillary oxygen saturation $\left(\mathrm{SaO}_{2}\right)$ on room air, defined as $\leq 90 \%$ for patients aged $>50$ years and $\leq 93 \%$ for patients 


\section{A. COVID-19 SEIMC Score}

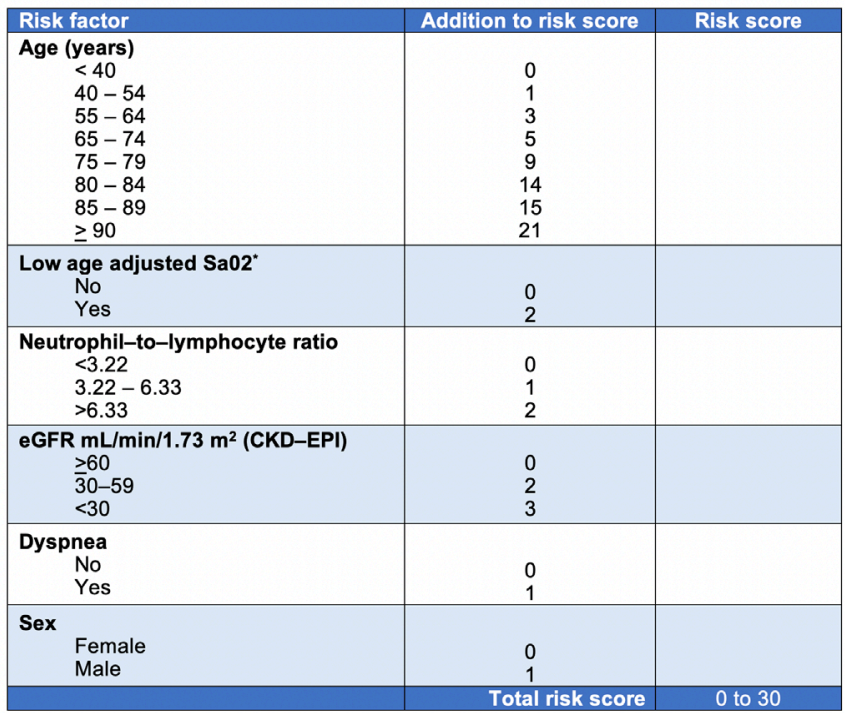

$" \leq 90 \%$ for patients aged $>50$ years and $\leq 93 \%$ for patients aged $\leq 50$ years

\section{B. 30-day mortality probability}

\begin{tabular}{|c|c|c|c|}
\cline { 3 - 4 } \multicolumn{2}{c|}{} & \multicolumn{2}{c|}{30 -day mortality probability } \\
\hline Total risk core & Risk category & Derivation cohort & Validation Cohort \\
\hline $\mathbf{3 - 5}$ points & Low & $0-2.1 \%$ & $0 \%$ \\
\hline $\mathbf{6 - 8}$ points & Hoderate & $4.7-6.3 \%$ & $0-3.7 \%$ \\
\hline $\mathbf{9 - 3 0}$ points & Very high & $10.6-19.5 \%$ & $4.5-12.7 \%$ \\
\hline
\end{tabular}

Figure 2 (A) Simple scoring system to predict 30-day mortality on presentation in hospitalised patients with COVID-19. (B) 30-day mortality probability according to the total risk score in the derivation cohort and the external validation cohort. CKD-EPI, Chronic Kidney Disease Epidemiology Collaboration equation; eGFR, estimated glomerular filtration rate; $\mathrm{SaO}_{2}$, oxygen saturation.

aged $\leq 50$ years $^{27} ;(5)$ tests results, including white cell count, neutrophil-to-lymphocyte ratio, platelet count, international normalised ratio (INR), estimated glomerular filtration rate (eGFR) measured by the Chronic Kidney Disease Epidemiology Collaboration (CKD-EPI) equation ${ }^{28}$ and serum concentrations of $\mathrm{C}$ reactive protein.

\section{Statistical analysis methods}

We followed recent recommendations to calculate the minimum sample size required for prediction model development. ${ }^{29} \mathrm{We}$ carried out a complete-case analysis (primary analysis) and two sensitivity analyses. In the first sensitivity analysis, we included all patients and missing values for predictors were considered as a separate category (missing indicator method). In the second sensitivity analysis, we also included all patients and missing values for predictors were left blank (equivalent to the lowest risk situation). No missing values for outcomes occurred in the DC or the external VC.

Continuous variables were categorised for the analysis. As mortality from COVID-19 among hospitalised patients is highly correlated with age, this variable was divided into 11 levels: $<40$ years that was the reference category and after that into 115 -year to 10 -year intervals up to $\geq 90$ years that was the last category. The neutrophil-to-lymphocyte ratio was categorised into tertiles: $<3.22$, which was the reference category, 3.22 to
6.33 , and $>6.33$. The eGFR in $\mathrm{mL} / \mathrm{min} / 1.73 \mathrm{~m}^{2}$ was grouped before the analysis into three categories: $>60$ (normal to mildly decreased eGFR), 30-59 (moderately to severely decreased eGFR) and <30 (severely decreased eGFR).

We used univariable and multivariable logistic regression in the derivation dataset to estimate the coefficients of each potential predictor of 30-day overall mortality. We fitted the final model by choosing predictors based on the strength of their unadjusted association with death. The model started with the predictor with the highest area under the receiver operating characteristics (AUROC) to predict 30-day mortality. Subsequently, the rest of the variables were introduced one by one, creating all the possible models of two independent variables, and the combination of higher AUROC was chosen. This process was repeated to form models of 3, 4 and more variables, always choosing the combination with the highest AUROC. The process stopped when the inclusion of a new variable in the model meant an increase lower than 0.005 unit in the AUROC.

We assessed the predictive performance of the model by examining measures of calibration and discrimination. We developed a calibration plot with estimates of the calibration slope and intercept. Calibration was also assessed using the Hosmer-Lemeshow test. Discrimination was examined by calculating its AUROC with the 95\% CI. We carried out internal validation through a bootstrap with 1000 random samples with replacement to estimate the model optimism and shrinkage factor.

The logistic regression model's coefficients were converted to a simplified score to facilitate its application in clinical practice. The score was developed, dividing each coefficient by the coefficient with the lowest value and rounding to an integer. Risk groups were created using the 30-day probability of death according to the simplified score. The sensitivity, specificity, positive and negative predictive values, and likelihood ratios were calculated for different scores.

The statistical analyses were performed using Stata software (V.15.0; Stata Corporation, College Station, Texas, USA).

\section{RESULTS}

\section{Participants}

The developing cohort included 4035 patients, of which 1074 (26.6\%) died and 2961 were alive within 30 days of hospital admission. The cohort size was more than twice the required for developing a clinical prognostic model (online supplemental appendix figure 1). The external VC included 2202 patients, $341(15.5 \%)$ died and 1861 were alive within 30 days of hospital admission. The median time to death since hospital admission was 10 (IQR 6-16) days in the -DC and 5 (IQR 3-10) days in the VC.

The characteristics of the participants, including demographics, presenting signs and symptoms, presence of lung infiltrates on chest radiograph, oxygenation and laboratory parameters, are shown in table 1. Patients in the DC were, on average, 9 years older, and more frequently, males than patients in the external VC. Statistically significant differences between the cohorts were found in all the analysed variables.

In the DC, targeted viral agents were administered to $82.0 \%$ of patients, including lopinavir/ritonavir (LPV/r) (70.4\%), hydroxychloroquine $(65.5 \%)$ and subcutaneous interferon-beta (29.2\%), usually in combination with LPV/r. In the external VC, targeted viral agents were administered to $65.3 \%$ of patients. The most frequent combination was hydroxychloroquine plus azithromycin (31.7\%), followed by hydroxychloroquine alone. Host-targeted agents in the DC included systemic corticosteroids 
Table 4 Prediction of 30-day mortality on presentation in hospitalised patients with COVID-19 according to the point score in the derivation cohort and in the external validation cohort

\begin{tabular}{|c|c|c|c|c|c|c|c|c|c|c|}
\hline \multirow{3}{*}{ Risk score } & \multicolumn{5}{|c|}{ Derivation cohort } & \multicolumn{5}{|c|}{ External validation cohort } \\
\hline & \multirow{2}{*}{ Total } & \multicolumn{4}{|c|}{ 30-day mortality } & \multirow{2}{*}{ Total } & \multicolumn{4}{|c|}{ 30-day mortality } \\
\hline & & \multicolumn{2}{|l|}{ Yes } & \multicolumn{2}{|l|}{ No } & & \multicolumn{2}{|l|}{ Yes } & \multicolumn{2}{|l|}{ No } \\
\hline 0 & 48 & 1 & 2.1 & 47 & 97.9 & 20 & 0 & 0.0 & 20 & 100 \\
\hline 1 & 139 & 0 & 0.0 & 139 & 100 & 68 & 0 & 0.0 & 68 & 100 \\
\hline 4 & 230 & 11 & 4.8 & 219 & 95.2 & 109 & 1 & 0.9 & 108 & 99.1 \\
\hline 5 & 254 & 16 & 6.3 & 238 & 93.7 & 107 & 4 & 3.7 & 103 & 96.3 \\
\hline 6 & 235 & 25 & 10.6 & 210 & 89.4 & 112 & 5 & 4.5 & 107 & 95.5 \\
\hline 7 & 237 & 32 & 13.5 & 205 & 86.5 & 80 & 8 & 10.0 & 72 & 90.0 \\
\hline 11 & 133 & 45 & 33.8 & 88 & 66.2 & 45 & 11 & 24.4 & 34 & 75.6 \\
\hline 12 & 94 & 36 & 38.3 & 58 & 61.7 & 26 & 5 & 19.2 & 21 & 80.8 \\
\hline 13 & 91 & 40 & 44.0 & 51 & 56.0 & 18 & 7 & 38.9 & 11 & 61.1 \\
\hline 14 & 75 & 32 & 42.7 & 43 & 57.3 & 19 & 5 & 26.3 & 14 & 73.7 \\
\hline 15 & 80 & 32 & 40.0 & 48 & 60.0 & 27 & 9 & 33.3 & 18 & 66.7 \\
\hline 16 & 83 & 36 & 43.4 & 47 & 56.6 & 32 & 10 & 31.3 & 22 & 68.8 \\
\hline 17 & 123 & 48 & 39.0 & 75 & 61.0 & 40 & 14 & 35.0 & 26 & 65.0 \\
\hline 18 & 97 & 51 & 52.6 & 46 & 47.4 & 49 & 16 & 32.7 & 33 & 67.3 \\
\hline 19 & 104 & 55 & 52.9 & 49 & 47.1 & 41 & 13 & 31.7 & 28 & 68.3 \\
\hline 20 & 96 & 50 & 52.1 & 46 & 47.9 & 23 & 9 & 39.1 & 14 & 60.9 \\
\hline 27 & 25 & 14 & 56.0 & 11 & 44.0 & 8 & 6 & 75.0 & 2 & 25.0 \\
\hline 28 & 20 & 19 & 95.0 & 1 & 5.0 & 3 & 1 & 33.3 & 2 & 66.7 \\
\hline 29 & 9 & 7 & 77.8 & 2 & 22.2 & 2 & 2 & 100 & 0 & 0.0 \\
\hline 30 & 6 & 6 & 100 & 0 & 0.0 & 0 & 0 & 0.0 & 0 & 0.0 \\
\hline Total & 3358 & 849 & 25.3 & 2509 & 74.7 & 1269 & 188 & 14.8 & 1081 & 85.2 \\
\hline
\end{tabular}

in $28.0 \%$ patients and tocilizumab in $9.4 \%$ patients. In the VC, corticosteroids and tocilizumab were administered to $13.3 \%$ and $2.3 \%$ patients, respectively.

\section{Model development and performance}

The number of participants in the DC without missing values for each predictor, the number of outcomes per predictor and the unadjusted associations between predictors and outcomes are shown in table 2.

The final prediction model generated without recoding missing values (3358 participants) is shown in table 3 . The variables used in the model to generate the score were those in table 2 . The model started with the variable age since it was the one with the highest predictive capacity for death at 30 days (AUROC $(95 \%$ CI) $0.768(0.753$ to 0.784$))$. The final input sequence of the variables to the model, following the procedure described in the Methods section, was age, low age-adjusted $\mathrm{SaO}_{2}$, neutrophilto-lymphocyte ratio, eGFR by the CKD-EPI equation, dyspnoea and sex.

The predicted probability of 30-day mortality was determined by the following equation:

$\mathrm{P}_{\text {death at day } 30}=1 /(1+\exp (-\mathrm{b}))$,

where $b=0$ (if age $<40)+0.082$ (if age 40-49) +0.471 (if age $50-54)+1.058$ (if age 55-59) +1.228 (if age 60-64) +1.655 (if age $65-69)+1.771$ (if age $70-74)+2.268$ (if age $75-79)+2.695$ (if age $80-84)+2.803($ if age $85-89)+3.103($ if age $>=90)+0.875$ (if low age-adjusted $\mathrm{SaO}_{2}$ ) +0.173 (if neutrophil-to-lymphocyte ratio 3.22-6.33) +0.657 (if neutrophil-to-lymphocyte ratio $>6.33)+0.498$ (if eGFR 30-59)+1.093 (eGFR <30)+0.414 (if dyspnoea) +0.466 (if male sex) -4.266 . 
Table 5 Simplified score to predict 30-day mortality in hospitalised patients with COVID-19 in the derivation cohort: sensitivity, specificity, likelihood ratios and predictive values for the different scores $(0-30)$ in the derivation cohort

\begin{tabular}{|c|c|c|c|c|c|c|c|c|c|}
\hline \multirow[b]{3}{*}{ Score } & \multicolumn{3}{|c|}{ Participants } & \multirow[b]{3}{*}{ Sen $(\%)$} & \multirow[b]{3}{*}{ Spe $(\%)$} & \multirow[b]{3}{*}{$+\mathrm{LR}$} & \multirow[b]{3}{*}{ 1/-LR } & \multirow[b]{3}{*}{ PPV (\%) } & \multirow[b]{3}{*}{ NPV $(\%$} \\
\hline & \multirow[b]{2}{*}{ Total } & \multicolumn{2}{|c|}{ Dying within 30 days } & & & & & & \\
\hline & & $\mathrm{N}$ & $\%$ & & & & & & \\
\hline 0 & 48 & 1 & 2.1 & 100 & 0 & 1 & - & 25.3 & - \\
\hline 1 & 139 & 0 & 0.0 & 99.9 & 1.9 & 1.018 & 15.900 & 25.6 & 97.9 \\
\hline 2 & 193 & 3 & 1.6 & 99.9 & 7.4 & 1.079 & 62.940 & 26.7 & 99.5 \\
\hline 3 & 215 & 10 & 4.7 & 99.5 & 15.0 & 1.171 & 31.810 & 28.4 & 98.9 \\
\hline 4 & 230 & 11 & 4.8 & 98.4 & 23.2 & 1.280 & 14.040 & 30.2 & 97.6 \\
\hline 5 & 254 & 16 & 6.3 & 97.1 & 31.9 & 1.425 & 10.830 & 32.5 & 97.0 \\
\hline 6 & 235 & 25 & 10.6 & 95.2 & 41.4 & 1.623 & 8.567 & 33.5 & 96.2 \\
\hline 7 & 237 & 32 & 13.5 & 92.2 & 49.7 & 1.835 & 6.398 & 38.3 & 95. \\
\hline 8 & 200 & 39 & 19.5 & 88.5 & 57.9 & 2.102 & 5.017 & 41.6 & 93.7 \\
\hline 9 & 191 & 53 & 27.7 & 83.9 & 64.3 & 2.351 & 3.986 & 44.3 & 92.2 \\
\hline 10 & 136 & 39 & 28.7 & 77.6 & 69.8 & 2.573 & 3.120 & 46.5 & 90.2 \\
\hline 11 & 133 & 45 & 33.8 & 73.0 & 73.0 & 2.776 & 2.732 & 48.4 & 89.0 \\
\hline 12 & 94 & 36 & 38.3 & 67.7 & 77.2 & 2.971 & 2.392 & 50.1 & 87.6 \\
\hline 13 & 91 & 40 & 44.0 & 63.5 & 79.5 & 3.099 & 2.178 & 51.2 & 86.6 \\
\hline 14 & 75 & 32 & 42.7 & 58.8 & 81.5 & 3.185 & 1.978 & 51.9 & 85.4 \\
\hline 15 & 80 & 32 & 40.0 & 55.0 & 83.3 & 3.286 & 1.850 & 52.6 & 84.5 \\
\hline 16 & 83 & 36 & 43.4 & 51.2 & 85.2 & 3.456 & 1.747 & 53.9 & 83.8 \\
\hline 17 & 123 & 48 & 39.0 & 47.0 & 87.0 & 3.628 & 1.642 & 55.1 & 82.9 \\
\hline 18 & 97 & 51 & 52.6 & 41.3 & 90.0 & 4.149 & 1.535 & 58.4 & 81.9 \\
\hline 19 & 104 & 55 & 52.9 & 35.3 & 91.9 & 4.346 & 1.421 & 59.5 & 80.8 \\
\hline 20 & 96 & 50 & 52.1 & 28.9 & 93.8 & 4.671 & 1.319 & 61.3 & 79.6 \\
\hline 21 & 74 & 51 & 68.9 & 23.0 & 95.7 & 5.287 & 1.242 & 64.1 & 78.6 \\
\hline 22 & 44 & 24 & 54.5 & 17.0 & 96.6 & 4.948 & 1.163 & 62.6 & 77.5 \\
\hline 23 & 37 & 23 & 62.2 & 14.1 & 97.4 & 5.373 & 1.134 & 64.5 & 77.0 \\
\hline 24 & 33 & 20 & 60.6 & 11.4 & 97.9 & 5.513 & 1.106 & 65.1 & 76.6 \\
\hline 25 & 23 & 14 & 60.9 & 9.1 & 98.4 & 5.835 & 1.083 & 66.4 & 76.2 \\
\hline 26 & 33 & 17 & 51.5 & 7.4 & 98.8 & 6.206 & 1.067 & 67.7 & 75.9 \\
\hline 27 & 25 & 14 & 56.0 & 5.4 & 99.4 & 9.710 & 1.051 & 76.7 & 75.7 \\
\hline 28 & 20 & 19 & 95.0 & 3.8 & 99.9 & 31.520 & 1.038 & 91.4 & 75.4 \\
\hline 29 & 9 & 7 & 77.8 & 1.5 & 99.9 & 19.210 & 1.015 & 86.7 & 75.0 \\
\hline 30 & 6 & 6 & 100 & 0.7 & 100 & - & 1.007 & 100 & 74.9 \\
\hline
\end{tabular}

The number of individuals in different risk categories was low (0-2 points; $380(11.3 \%))$, medium (3-5 points; $699(20.8 \%))$, high (6-8 points; 672 (20.0\%)) and very high (9-30 points; 1607 $(47.9 \%))$

-LR, negative likelihood ratio; +LR, positive likelihood ratio; NPV, negative predictive value; PPV, positive predictive value; Sen, sensitivity; Spe, specificity.

The final model showed good calibration across the range of risk (figure 1), and the goodness-of-fit Hosmer-Lemeshow test was $11.21, p=0.1902$ vs $p<0.05$, confirming the calibration of the model. Using bootstrapping techniques, an optimism of 0.006 and a shrinkage factor of 0.968 were estimated. In 600 of the samples (60\%), the Hosmer-Lemeshow test was significant.

The AUROC (95\% CI) of the model for prediction of 30-day mortality was $0.822(0.806$ to 0.837$)$ in the DC and 0.845 $(0.819$ to 0.870$)$ in the external VC (online supplemental appendix table 2).

\section{Simplified score development and performance}

The simplified point score (from 0 to 30 ) resulting from the division of the regression coefficients of predictors in the final model by the coefficient of age 40-49, which was the lowest value among all coefficients, is shown in figure $2 \mathrm{~A}$. The prediction of 30-day mortality on presentation in hospitalised patients with COVID-19 according to the point score in the DC and in the external VC is shown in table 4.

The AUROC (95\% CI) of the simplified score for prediction of 30-day mortality was $0.806(0.790$ to 0.821$)$ in the DC and $0.831(0.806-0.856)$ in the external VC (online supplemental appendix table 2 ). The sensitivity, specificity, positive and negative predictive values, and likelihood ratios for the different scores in the DC and external VC are shown in table 5 and online supplemental appendix table 3 , respectively.

We considered the risk of 30-day mortality as low with $0-2$ points $(0 \%-2.1 \%)$, moderate with 3-5 (4.7\%-6.3\%), high with 6-8 (10.6\%-19.5\%) and very high with 9-30 (27.7\%-100.0\%) (figure 2B). Kaplan-Meier survival plots for the different 30-day mortality risk categories according to the simplified score in the DC and VC are shown in online supplemental appendix figure 2. 


\section{Sensitivity analyses}

\section{Sensitivity analysis 1}

When we generated the final prediction model recoding missing values for predictors as a separate category, the AUROC $(95 \% \mathrm{CI})$ was 0.822 (0.809 to 0.836 ) in the DC and 0.850 (0.831 to 0.867$)$ in the external VC. Likewise, when we applied the same approach to the simplified point score, the AUROC $(95 \% \mathrm{CI})$ was $0.805(0.791$ to 0.820$)$ in the DC and 0.848 (0.830 to 0.866$)$ in the external VC (online supplemental appendix table 2).

\section{Sensitivity analysis 2}

When we applied the final prediction model to all patients, and missing values for predictors were left blank (equivalent to the lowest risk situation), the AUROC (95\% CI) was 0.818 (0.805 to $0.832)$ in the DC and $0.859(0.842$ to 0.876$)$ in the external VC. Likewise, when we applied the same approach to the simplified point score, the AUROC (95\% CI) was 0.806 (0.791 to 0.820) in the DC and 0.849 ( 0.831 to 0.866$)$ in the external VC (online supplemental appendix table 2).

\section{DISCUSSION}

The COVID-19 SEIMC score for predicting 30-day mortality of patients attending hospital emergency rooms was developed and externally validated with two large datasets from patients hospitalised with laboratory-confirmed COVID-19 in Spain. The predictors were age, low age-adjusted $\mathrm{SaO}_{2}$, neutrophil-tolymphocyte ratio, eGFR by the CKD-EPI equation, dyspnoea and sex. The model showed good performance in both the DC and the external VC and permitted an easy stratification of patients into four risk categories.

Our prediction model uses widely accessible clinical and laboratory data, and its simplicity would allow clinicians to perform rapid risk stratification of patients with COVID-19. Of note, our model does not take into account comorbidities, which have been associated with worse COVID-19 prognosis in descriptive studies and included in most prognostic prediction models reported to date. ${ }^{13}$ 15-22 In our study, underlying diseases such as hypertension, obesity, liver cirrhosis, chronic neurological disorder, active neoplasia and dementia were independently associated with an increased risk of 30-day mortality. However, none of these conditions improved the model's discrimination capacity and, following the principle of parsimony, were discarded.

Once again, our study highlights the extraordinary impact of age on COVID-19 mortality, which is, to the best of our knowledge, unparalleled in infectious diseases. For example, our score would classify a 65 -year-old male patient attending the emergency room - regardless of the results of the other variables-as a high-risk category with a 30-day mortality probability that could reach up to $19.5 \%$. For younger patients, our score also shows the importance of basic laboratory parameters. A 55 -year-old man without dyspnoea, normal $\mathrm{SaO}_{2}$ and normal renal function but with a neutrophil-to-lymphocyte ratio higher than 6.33 would also be classified as high risk.

At the time of writing, an eight variable mortality score developed and validated in a UK prospective cohort of 57824 patients admitted to hospital with COVID-19, the 4C Mortality Score, has been published. ${ }^{30}$ Some of the variables included in this score, such as respiratory rate, Glasgow Coma Scale score and urea, are not available in the COVID-19@Database precluding the cross-validation the 4C Mortality Score in our population.

Our study is limited, as is the case with other reported studies, by the retrospective capture of data. Another potential limitation is that it was based exclusively on predictors from patients attending hospital emergency rooms. However, we believe that our score could be applied in primary care settings if capillary $\mathrm{SaO}_{2}$ and routine laboratory tests such as blood counts and serum creatinine could be determined. Finally, our score was derived from hospitalised patients in a single country, raising the question about their transportability to other countries, a common limitation to all currently described prognostic models of COVID-19. We believe that it would be of interest to carry out cross-validation between the SEIMC COVID-19 score and other scores in a large multinational dataset.

Our study has several strengths. In contrast with the majority of prior published prognostic models, ours adhere to the TRIPOD statement's recommendations. Besides, the large sample size and the high number of events in the DC minimise the risk of model overfitting, a general limitation of previous studies. Our model's strengths also include the calibration, the internal validation by bootstrapping rather than by random split of the DC and the validation in a large external cohort. Finally, the sensitivity analyses exploring different approaches for missing values for predictors did not modify the model's performance, suggesting that missing values in both cohorts occurred at random.

The SEIMC COVID-19 score could be a useful triage tool enabling quick decision-making for patients with COVID-19. For example, patients in the low-risk category are likely suitable for outpatient care, whereas hospital admission or intensive or high dependency care should be considered for patients in high and very high-risk categories. Besides, management in emergency department observation units or makeshift medicalised facilities could be considered for patients in the moderate risk category. Another potential application of the SEIMC COVID-19 score is the risk stratification of patients with COVID-19 in observational studies or clinical trials.

Our study showed that the COVID-19 SEIMC score, a simple prediction tool using readily available clinical and laboratory data results, could identify the probability of 30-day mortality with a high degree of accuracy among patients with COVID-19.

\section{Author affiliations}

${ }^{1}$ Clinical Microbiology and Infectious Diseases, Hospital General Universitario Gregorio Marañón, Instituto de Investigación Sanitaria Gregorio Marañón (liSGM), Madrid, Spain

${ }^{2}$ Clinical Pharmacology, Hospital Universitario La Paz, Instituto de Investigación Hospital Universitario La Paz (IdiPAZ), Universidad Autónoma de Madrid, Madrid Spain

${ }^{3}$ Infectious Diseases, Internal Medicine Service, Hospital Universitario Infanta Leonor, Instituto de Investigación Sanitaria Gregorio Marañón (liSGM), Madrid, Spain ${ }^{4}$ Infectious Diseases and Microbiology Unit, Hospital Universitario Virgen Macarena, Instituto de Biomedicina de Sevilla (IBiS), Department of Medicine, Universidad de Sevilla, Sevilla, Spain

${ }^{5}$ Fundación Investigación Biomédica, Hospital General Universitario Gregorio Marañón, Instituto de Investigación Sanitaria Gregorio Marañón (IISGM), Madrid, Spain

${ }^{6}$ National Centre for Epidemiology, Institute of Health Carlos III, Madrid, Comunidad de Madrid, Spain

${ }^{7}$ Infectious Diseases, Hospital Universitario de Bellvitge, Instituto de Investigación Biomédica de Bellvitge (IDIBELL), Universitat de Barcelona, Barcelona, Spain

${ }^{8}$ Infectious Diseases, Hospital Universitario Virgen del Rocío, Instituto de Biomedicina de Sevilla (IBiS), Department of Medicine, Universidad de Sevilla, Sevilla, Spain

${ }^{9}$ Fundación SEIMC-GESIDA, Madrid, Spain

${ }^{10}$ Infectious Diseases Unit, Internal Medicine Service, Hospital Universitario La Paz, Instituto de Investigación Hospital Universitario La Paz (IdiPAZ), Madrid, Spain

Acknowledgements Members of the COVID-19@Spain Study Group and the COVID@HULP Working Group that have made substantial contributions by data collection are listed in online supplemental appendix tables 4 and 5 . We want to express our gratitude to the patients whose records were used in this study, and to the staff of the participating centres for their commitment to the care of patients through the COVID-19 outbreak. 
Collaborators COVID-19@Spain and COVID@HULP Study Groups: Esther Aznar; Pedro Gil; Patricia Gonzalez; Clara Muñoz; Juan C López; Margarita Ramírez-Schacke; Isabel Gutiérrez; Francisco Tejerina; Teresa Aldámiz-Echevarría; Cristina Díez; Chiara Fanciulli; Leire Pérez-Latorre; Francisco Parras; Pilar Catalán; María E García-Leoni; Isabel Pérez-Tamayo; Luis Puente; Jamil Cedeño; Marta Díaz; Fernando de la Calle; Marta Arsuaga; Elena Trigo; M del Mar Lago; Rosa de Miguel; Julen Cadiñaños; Carmen Busca; Alfredo Mican; Marta Mora; Juan Carlos Ramos; Belén Loeches; José I Bernardino; Julio García; Ana Such; Elena Álvaro; Elsa Izquierdo; Juan Torres; Guillermo Cuevas; Jesús Troya; Beatriz Mestre; Eva Jiménez; Inés Fernandez; Ana J Tebar; Fátima Brañas; Jorge Valencia; Mario Pérez; Marta Alvarado; Pablo Ryan; M Antonia Sepúlveda; Carmen Yera; Pilar Toledano; Verónica Cano; Sadaf Zafar; Gema Muñiz; Inmaculada Martín; Helena Mozas; Ana Alguacil; M Paz García; Ana I Peláez; Elena Morcillo; Josune Goikoetxea; M José Blanco; Javier Nieto; Mikel del Álamo; Isabel A; Pérez; Inés Pérez; Rafael Silvariño; Jon Ugalde; Víctor Asensi; Lucia Suárez; Silvia Suárez; Carmen Yllera; Vicente Boix; Marcos Díez; Melissa Carreres; Cristina Gómez-Ayerbe; Javier Sánchez-Lora; José L Velasco; María López-Jódar; Jesús Santos; Jesús Ruiz; lanire Virto; Vanessa Alende; Ruth Brea; Sonia Vega; Estel Pons; Oscar Del Río; Silvia Valero; Judit Villar-García; Joan Gómez-Junyent; Hernando Knobel; M Cecilia Cánepa; Silvia Castañeda; Luisa Sorli; Roberto Güerri-Fernández; María Milagro; Juan P Horcajada; Elisa García; Encarnación Moral; Alicia Hernádez; Esther García; Carmen Sáez; Zineb Karroud; José Hernández; David Vinuesa; José L García; José A Peregrina; María Novella; Cristina Hernández; José Sanz; Ramón Pérez; Rodrigo Sierra; David Alonso; Aida Gutiérrez; Alberto Arranz; Juan Cuadros; Melchor Álvarez de Mon; Vicente F Díaz De Brito; Montserrat Sanmarti; Aina Gabarrell; Daniel Molina; Sergio España; Jonathan Cámara; Albert Sabater; Laura Muñoz; Paula Sáez; Esperanza Bejaranao; Marco A Sampere; Salvador Álvarez; Ignacio De los Santos; Lucio García-Fraile; Miguel Sampedro; Ana Barrios; Carlos Rodríguez; Daniel Useros; Almudena Villa; Javier Oliver; Alexia C Espiño ; Jesús Sanz; María Rexach; Ivette Abascal; Ana del C Pérez; Clara Sala; Susana Casas; Cecilia Tortajada; Carmina Oltra; Mar Masiá; Félix Gutiérrez; Ana Ferrer; Carlos Bea; Miguel Pedromingo; M Ángeles Garcinuño; Silvana Fiorante; Sergio Pérez; Pilar Hernández; Violeta A Alastrué; M Carmen Fariñas; Claudia González; Francisco Arnaiz; Jorge Calvo; Mónica Gonzalo; Francisco Mora; Ana Milagro; Miriam Latorre-Millán; Antonio Rezusta; Ana Martínez; Yolanda Meije; Alejandra Duarte; Julia Pareja; Mercedes Clemente; Juan E Losa; Ana Vegas; M Teresa Pérez-Rodríguez; Alexandre Pérez; Moncef Belhassen-García; Beatriz Rodríguez-Alonso; Amparo López-Bernus; Cristina Carbonell; Rafael Torres; Juan Catón; Blanca Alonso; Sara L Kamal; Lucia Cajuela; David Roa; Miguel Cervero; Alberto Orejas; Juan P Avilés; Lidia Martín; Iván Pelegrín; Rosana Rouco;Jorge Parra; Violeta Ramos; Jessica Abadía; Juan Salillas; Robert Torres; Miguel Torralba; Alberto Serrano; Sergio Gilaberte; Marina Pacheco; Mónica Liébana; Sara Fernández; Álvaro Varela; Henar Calvo; Patricia Martínez; Patricia González- Ruano; Eduardo Malmierca; Isabel Rábago; Beatriz Pérez-Monte; Ángeles García; Pere Comas; Merce Sirisi; Richard Rojas; José L Díaz de Tuesta; Ruth Figueroa; Ander González; Remedios Alemán; M del Mar Alonso; Oscar Sanz; Karim M Ramírez; Melchor Riera; Helem H Vilchez; Francesc Albertí; Ana I Cañabate; Víctor J Moreno; Silvia Álvarez; Beatriz Álvarez; Alejandro García; Elena Isaba; Covadonga Morcate; Andrea Pérez; Lucía Ramos; Laura Castelo; María Rodríguez; Mónica González; Efrén Sánchez; Enrique Míguez; Javier De la Torre; José M García de Lomas; Elena Morte; Silvia Loscos; Ana Camón; Lucía Gómez; Lucia Boix; Beatriz Dietl; Iris Pedrola; Amparo Blasco; Cristina López; Esther Fraile; Tomás Tosco; María Aroca; José T Algado; Ana M Garijo; Concepción Amador; Pilar Retamar; Adoración Valiente; Luis E; López-Cortés; Jesús Sojo; Belén Gutiérrez-Gutiérrez; José Bravo-Ferrer; Elena Salamanca; Zaira R; Palacios; Patricia Pérez-Palacios; Enrique Peral; José A Pérez de León; Jesús Sánchez-Gómez; Lucía Marín-Barrera; Domingo García-Jiménez; Gabriela Abelenda-Alonso; Carmen Ardanuy ; Alba Bergas; Guillermo Cuervo; M Ángeles Domínguez; Miguel Fernández-Huerta; Carlota Gudiol ; Laia Lorenzo-Esteller; Jordi Niubó; Sandra Pérez-Recio; Daniel Podzamczer; Miquel Pujol; Alexander Rombauts; Núria Trullen; Miguel Salavert; Iván Castro; Adriana Hernández; Raquel Martínez; Marta Navarro; Sonia Calzado; Manuel Cervantes; Aina Gomila; Oriol Gasch; M Luisa Machado; Eva Van den Eynde; Luis Falgueras; M del Carmen Navarro; Esteban Martínez; M Ángeles Marcos; Mar Mosquera; José L Blanco; Montserrat Laguno; Jhon Rojas; Ana González-Cordón; Alexy Inciarte; Berta Torres; Lorena De la Mora; Alex Soriano; Olalla Martínez; Virginia Pérez; Alfonso Cabello; Nerea Carrasco; Beatriz Álvarez; Elizabet Petkova; Miguel Górgolas; Laura Prieto; Irene Carrillo; Sara Heili; Felipe Villar; Ricardo Fernández; José Milicua; Virginia Fernández; Carlos J Dueñas; Cristina Hernán; Fernando González-Romo; Paloma Merino; Alba Rueda; Jorge Martínez; Sara Medrano; Irene Díaz; Yolanda Posada; Alberto DelgadoIribarren; Joaquín López-Contreras; Pablo Pascual; Virginia Pomar; Nuria Rabella; Natividad Benito; Pere Domingo; Xavier Bonfill; Rafael Padrós; Mireia Puig; Jordi Mancebo; Mercè Gurguí; Melania Î̃igo; Alejandra Pérez; Patricia Sorní ; Nora Izko; Francisco J Membrillo; María Simón; Maribel Zamora; Yolanda Martínez; Pablo Fernández-González; Francisco Alcántara; Alejandro Aguirre; Elena López; Germán Ramírez-Olivencia; Miriam Estébanez; Ester Sáez de Adana; Joseba Portu; Juan C Gainzarain; Zuriñe Ortiz de Zárate; Miguel A Moran; Andrés Canut; Silvia Hernáez; Leire Balerdi; Cristina Morales; Miguel Corral; Zeltia Valcarce; Noelia Arenal ; Raquel E Rodríguez; Laura Iglesias; Beatriz Loureiro; Adrián Sánchez; Juan Espinosa; Benito Almirante; Marta Miarons; Júlia Sellarés; María Larrosa; Sonia García; Blanca Marzo; Miguel Villamarín; Nuria Fernández; Conchita Pérez-Jorge; Elena Resino; Andrea
Espigares; Teresa Álvarez de Espejo; Iván Navas; M Isabel Quijano; Luis A Nieto; Guillermo Jiménez; Mercedes Guillamón; Josefina García; Constanza Muñoz; Ana Mariño; Nieves Valcarce; Alex Smithson; Cristina Chico; Adriana Sánchez; Eva P García; Isabel Jiménez; Guillermo Estrada; María Lorén; Nuria Parra; Carmen Martínez; Aránzazu Villasante; Teresa García; M José Ruiz; Marta Robledo; Juan C Abad; José R Muñoz ; Montaña Jiménez; Javier Coy; Inmaculada Poquet; Marta Santos; Virginia Naranjo; Tamara Manso; Delia Quilez; Gema Barbeito; M Jesús Domínguez; Laura Mao; Rodrigo Alonso; Jose D Ampuero; Raquel Barrós; M Aránzazu Galindo; Lourdes Herrera; Rocío Martínez; Sara Rodrigo; Cristóbal M Rodríguez; Eva M Romay; Roi Suárez; Maialen Ibarguren; José M Marimón; Loreto Vidaur; Xabier Kortajarena; Miriam García; Asier Aranguren; Maria Álvarez; Cintia M Martínez; Francisco Rodríguez; Francisco Muñoz; Elena Chamarro ; Merce Cardona; Ismail Zakariya-Yousef; Marta Rico; Jara Llenas; M Carmen Sánchez; Ana Fernández; Jorge Calderón; Marcos López; Antonio Ramos; Elena Múñez; Alejandro Callejas; José M Vázquez; Itziar Diego; Esther Expósito; Jorge Anel; Raquel Álvarez; Lucía Fernández; Roberto Vates; Andrés F Cardona; Pablo Marguenda; Gabriel Gaspar; Elena M Aranda; Blanca Martínez; Daniel Roger; Irene Martín; André Barbosa; Iván Piñero; Alberto Bahamonde; Paula Runza; Eva Talavera; Marta Lamata; Ainhoa Urrutia; Lorea Arteche; Elisabet Delgado; Virginia Molina; Sarah Caro; Gema Domínguez; Carolina Roldán; Carmen Herrero; Luis Force; Raquel Aranega; Arantzazu Mera; M Roca Toda; Nicolas Merchante ; Eva M León; José L Del Pozo; Josefa Serralta; Ginger G Cabrera; Mario Fernández-Ruiz; José M Aguado; Guillermo Maestro; José M Cisneros; Manuela Aguilar-Guisado; Teresa Aldabó; M Dolores Avilés; Claudio Bueno; Elisa Cordero-Matía; Ana Escoresca; Lydia Gálvez-Benítez; Carmen Infante; Guillermo Martín; Julia Praena; Cristina Roca; Celia Salamanca; Alejandro Suárez-Benjumea; Pilar Vizcarra; Carmen Quereda; Mario J Rodriguez; Francesca Gioia; Francesca Norman; Santos Del Campo; Rafael Cantón; José A Oteo; Paula Santibáñez; Cristina Cervera; Carlos Ruiz; José R; Blanco; José M Azcona; Concepción García; Jorge Alba; Valvanera Ibarra; Mercedes San Franco; Luis Metola; Héctor Meijide; Silvia Paulos; Justo Menéndez; Paula Villares; Lara Montes; Álvaro Navarro; Anna Ferrer; M de la Luz Padilla; Lucy Abella; Marcelino Hayek; Antonio García; Carolina Hernández; Andrés J Ruiz; Isabel Barrio; Alí Martakoush; Agustín Rojas-Vieyra; Sonia García; Mercedes Villarreal; Marta Vizcaíno; M Pilar García; Ana Lérida; Natalia Carrasco; Beatriz M Sanjuan; Lydia Martín; Camilo Sanz; Belén Alejos; Cristina Moreno; Marta Rava; Carlos Iniesta; Rebeca Izquierdo; Inés Suárez-García; Asunción Díaz; Marta Ruiz-Alguero; Victoria Hernando; J Frías; E Ramírez; A Martín-Quirós; M Quintana; I Mingorance; F Arnalich; F Moreno; JC Figueiras; N García-Arenzana; M Dolores Montero; MP Romero; C Toro-Rueda; S GarcíaBujalance; G Ruiz-Carrascoso; E Cendejas-Bueno; I Falces-Romero; F Lázaro-Perona; M Ruiz-Bastián; A Gutiérrez-Arroyo; P Girón De Velasco-Sada; E Dahdouh; B Gómez-Arroyo; C García-Sánchez; V Guedez-López; I Bloise; M Alguacil-Guillén; M Gracia Liras-Hernández; M Sánchez-Castellano; P García-Clemente; P GonzálezDonapetry; S San José-Villar; M de Pablos; R Gómez-Gil; M Corcuera; A; Rico-Nieto; B; Loeches; J Mingorance; I García Rodríguez; F Moreno; A Herrero; D Prieto Arribas; P Oliver-Saez; R Mora; P Fernández-Calle; MJ Alcaide; J Diaz-Garzón; B FernándezPuntero; R Nuñez; G Crespo; O Rodriguez; H Mendez; M Duque; R Gomez; M Sanz de Pedro; L Pascual; M Segovia; JM Iturzaeta; M Rodriguez; A García; MA Martinez; B Fabre; E Martinez; I Moreno; N Rodriguez; D Ortiz; M Simon; IG Tomoiu; C Pizarro; B Montero; AL Qasem; M Gomez; I Casares; A Buño; M Martí de Gracia; L Parra Gordo; A Diez Tascón; S Ossaba Vélez; I Pinilla; E Cuesta; M Fernández-Velilla; M Torres; G Garzón; V Pérez; A Quintás; I San Juan; I Cantero; C Pérez; M Castro; L Hernández; T Pedraz; E Fernández; C García; A Robustillo; I Fernández; M Noguerol; A Martínez; M González; R Cabrera; R Mayayo; R Marín; V Lo-lacono; M Lerín; P Romero; B Reche; R Tejada; M Rico; R Deza; S Fabra; I Arroyo; L Dani; L Labajo; R Soriano; L López; E Calvin; S Martñinez; L López-Tappero; M Pilares; 0 González; G Bejarano; A Iglesias; Y Tung; C Maroun; R Bravo; M Silvestre; F Perdomo; B Alonso; B Antón; I Arenas; C Cabré; F Marqués; E Muñoz; MA Molina; N Cancelliere; S Pastor; L Frade; P López; I García; C Fernández Capitán; JJ González Garcia; JM Herrero; MA Quesada Simón; A Robles Marhuenda; II Bernardino; M Mora; C Soto Abanedes; AM Noblejas Mozo; JC Ramos; B Diaz Pollán; MJ Jaras Hernandez; E Martinez Robles; A Moreno Fernandez; R Montejano; A Sanchez Purificación; JC Martin Gutiérrez; PL Martinez Hernández; F la Calle; M Arsuaga; M Diaz Menéndez; E Trigo; C Busca Arenzana; T Sancho Bueso; A Lorenzo Hernández; B Gutierrez Sancerni; G; Salgueiro; L; Martin Carbonero; J; Mostaza; R; de Miguel; M;A; Martinez-López; V; Hontañon; A; Menéndez; J; Cadiñanos; I Alvarez Troncoso; A Castellano; C Marcelo Calvo; I Vives Beltrán; L Ramos Ruperto; G Daroca Bengoa; MM Arcos Rueda; I Vasquez Manau; P Fernández Cidón; C Rosario Herrero Gil; E Palmier Peláez; Y Untoria Tabares; C; Lahoz; E; Estirado; C Hernández; F; Garcia-Iglesias; E; Monteoliva; M Martínez; M; Varas; T; González Alegre; ME Valencia; V Moreno; ML Montes; S Alcolea; I Cabanillas; C Carpio; R Casitas; I Fernández-Bujarrabal; I Fernández Navarro; I Fernández Lahera; C García Quero; M Hidalgo; R Galera; F García Río; L Gómez Carrera; M Gómez Mendieta; A Mangas; E Martínez Cerón; M Martínez Redondo; Y Martínez Abad; A Martínez-Verdasco; C Plaza; S Quirós; D Romera; D Romero; B Sánchez; A Santiago; C Villasante; E Zamarrón; V Arnalich; P Mariscal; A Falcone; D Laorden; MC Prados; R Álvarez-Sala; A García; C Arévalo; C Gutiérrez; IC Figueira; M Quintana; S Yus; MJ Asensio; M Sánchez; JM Añón; I Manzanares; A García de Lorenzo; E Perales; B Civantos; L Cachafeiro; A Agrifoglio; B Estébanez; E Flores; M Hernández; P Millán; M Rodríguez; C Gutiérrez; K Nanwani; B Arizcun; E Pérez; D Rodríguez; M Sánchez; U 
Quesada; C Román; P Dorao; E Alvarez-Rojas; JJ Menendez-Suso; C Verdu; A Gómez-Zamora; C Schuffelman; B Calderón; M Laplaza; M del Rio; I Amores; M Rodriguez-Rubio; P de la Oliva; I Ruiz; S Rosillo; 0 González; A Iniesta; I Ponz; JM Muñoz Ramón; MC Hernández Gancedo; R Uña Orejón; P Sanabria Carretero; I Moreno Gomez-Limón; A Seiz-Martinez; E Guasch-Arévalo; C Martín-Carrasco; E Alvar; L Serrá; F lannucelli; J Latorre; S Casares; I Valbuena; L Díaz Díez Picazo; C Rodríguez Roca: 0 Cervera; E García de las Heras; P Durán; C Castro; C Manrique de Lara; J Veganzones; A López Tofiño; E Fernandez-Cerezo; S Zurita; S Casares; M López-Martinez; T Prim; J Alvárez del Vayo; G Alcaraz; L Castro; J Yagüe; S Díaz-Carrasco; P González-Pizarro; A Montero; FJ Sagra; A Suárez; L Díez Porres; M Varela Cerdeira; A Alonso Babarro; F Abellán; J Alonso; A Álvarez; M Archinà; S Arribas; T Baselga; P Barco; N Barrera; L Barrera; A Bartrina; G Bassani; P Betancort; Blanco; C Blasco; L Brieba; F Cadenas; P Carrera; C Cascajares; A Catino; R Cavallé; D Ceniza; Y Conde; L Currás; M Daltro; A Esteban; M Fernández; I Ferrer; L Regaño; P Galindo; S Garcia-Bellido; C García-Mochales; T Gómez; C Gómez; N González; S González; I Guisández; P Hernández; R Hernando; I Llorente; A Marín; P López; L Mejuto; M Palma; A Peña; L Platero; D Pujol; M Ramírez; M Redondo; F Reinoso; A Rodríguez; A Rodríguez; L Romero; S Sánchez; M Sánchez; P Serrano; H Serrano; T Silva; E Soria; A Suárez; B Tejero; A Torrecillas; J Torres; M Valentín-Pastrana; A Villanueva; M Virgós; M Yagüe; N Yustas; J Montserrat; I Queiruga; A Rodriguez Mariblanca; L Martínez de Soto; M Urroz; E Seco; M Zubimendi; S Stuart; L Díaz; I García; MT García Morales; A Martín-Vega.

Contributors Study conception and design: JB, JRB and JRA. Acquisition, analysis or interpretation of data: JB, AMB, PR, JRB, JMB, IJ, JC, JP, AJC, MY and JRA.

Statistical analysis: JMB, JB, IJ. Drafting of the manuscript: JB. Critical revision of the manuscript for important intellectual content: JB, AMB, PR, JRB, JMB, IJ, JC, JP, AJC, $M Y$ and JRA. Administrative, technical or material support: JB, AMB, PR, MY and JRA. Study supervision: JB, AMB, PR, JRB, JMB, IJ, JC, JP, AJC, MY and JRA are the guarantors of the study. The corresponding author attests that all listed authors meet authorship criteria and that no others meeting the criteria have been omitted.

Funding This work was supported by Fundación SEIMC/GeSIDA. The funders had no role in study design, data collection, data interpretation or writing of the manuscript. JB, JRB, IJ, JC, JP and JRA received funding for research from Plan Nacional de I+D+i 2013-2016 and Instituto de Salud Carlos III, Subdirección General de Redes y Centros de Investigación Cooperativa, Ministerio de Ciencia, Innovación y Universidades, cofinanced by the European Development Regional Fund "A way to achieve Europe", Operative program Intelligent Growth 2014-2020 Spanish AIDS Research Network (RIS) (RD16/0025/0017 (JB), RD16/0025/0018 (JRA), RD16CIII/0002/0006 (IJ)). Spanish Network for Research in Infectious Diseases (REIPI) (RD16/0016/0001 (JRB), RD16/0016/0005 (JC) and RD16/0016/0009 (JP)).

Competing interests JB reports grants and personal fees from GILEAD, MSD and ViiV Healthcare; and personal fees from JANSSEN, outside the submitted work. PR reports grants and personal fees from GILEAD and MSD; and personal fees from AbbVie and ViiV Healthcare, outside the submitted work. IJ reports personal fees from GILEAD and ViiV Healthcare, outside the submitted work. JRA reports grants and personal fees from GILEAD and ViiV Healthcare; and personal fees from ALEXA, MSD, JANSSEN, SERONO and TEVA, outside the submitted work. The remaining authors have nothing to disclose.

\section{Patient consent for publication Not required.}

Ethics approval The projects COVID19@Spain and COVID19@HULP were approved by the Ethics Committee for Research with Medicines of Hospital General Universitario Gregorio Marañón and Hospital Universitario La Paz, respectively. Both committees waived informed consent for the collection of clinical data.

Provenance and peer review Not commissioned; externally peer reviewed.

Data availability statement All data relevant to the study are included in the article or uploaded as supplementary information.

Open access This is an open access article distributed in accordance with the Creative Commons Attribution Non Commercial (CC BY-NC 4.0) license, which permits others to distribute, remix, adapt, build upon this work non-commercially, and license their derivative works on different terms, provided the original work is properly cited, appropriate credit is given, any changes made indicated, and the use is non-commercial. See: http://creativecommons.org/licenses/by-nc/4.0/.

\section{ORCID iD}

Juan Berenguer http://orcid.org/0000-0001-8541-8200

\section{REFERENCES}

1 Chen N, Zhou M, Dong X, et al. Epidemiological and clinical characteristics of 99 cases of 2019 novel coronavirus pneumonia in Wuhan, China: a descriptive study. Lancet 2020;395:507-13

2 Guan W-J, Ni Z-Y, Hu Y, et al. Clinical characteristics of coronavirus disease 2019 in China. N Engl J Med 2020;382:1708-20.
3 Wu C, Chen X, Cai Y, et al. Risk factors associated with acute respiratory distress syndrome and death in patients with coronavirus disease 2019 pneumonia in Wuhan, China. JAMA Intern Med 2020;180:934

4 Grasselli G, Zangrillo A, Zanella A, et al. Baseline characteristics and outcomes of 1591 patients infected with SARS-CoV-2 admitted to ICUs of the Lombardy region, Italy. JAMA 2020;323:1574-81.

5 Zhou F, Yu T, Du R, et al. Clinical course and risk factors for mortality of adult inpatients with COVID-19 in Wuhan, China: a retrospective cohort study. Lancet 2020;395:1054-62.

6 Docherty AB, Harrison EM, Green CA, et al. Features of 20133 UK patients in hospital with covid-19 using the ISARIC WHO Clinical Characterisation Protocol: prospective observational cohort study. BMJ 2020;369:m1985.

7 Liang W, Guan W, Chen R, et al. Cancer patients in SARS-CoV-2 infection: a nationwide analysis in China. Lancet Oncol 2020;21:335-7.

8 Simonnet A, Chetboun M, Poissy J, et al. High prevalence of obesity in severe acute respiratory syndrome Coronavirus-2 (SARS-CoV-2) requiring invasive mechanical ventilation. Obesity 2020:28:1195-9.

9 Shi S, Qin M, Shen B, et al. Association of cardiac injury with mortality in hospitalized patients with COVID-19 in Wuhan, China. JAMA Cardiol 2020:5:802

10 RH D, Liang LR, Yang CQ. Predictors of mortality for patients with COVID-19 pneumonia caused by SARS-CoV-2: a prospective cohort study. Eur Respir J2020;55.

11 Collins GS, Reitsma JB, Altman DG, et al. Transparent reporting of a multivariable prediction model for individual prognosis or diagnosis (TRIPOD): the TRIPOD statement. Ann Intern Med 2015;162:55-63.

12 Pencina MJ, Goldstein BA, D'Agostino RB. Prediction Models - Development, Evaluation, and Clinical Application. N Eng/ J Med 2020:382:1583-6.

13 Wynants L, Van Calster B, Collins GS, et al. Prediction models for diagnosis and prognosis of covid-19 infection: systematic review and critical appraisal. BMJ 2020;369:m1328.

14 Sperrin M, Grant SW, Peek N. Prediction models for diagnosis and prognosis in Covid-19. BMJ 2020;369:m1464.

15 Wu G, Yang P, Xie Y, et al. Development of a clinical decision support system for severity risk prediction and triage of COVID-19 patients at hospital admission: an international multicentre study. Eur Respir J 2020;56. doi:10.1183/13993003.011042020. [Epub ahead of print: 2008 2020].

16 Dong Y-M, Sun J, Li Y-X, et al. Development and validation of a nomogram for assessing survival in patients with COVID-19 pneumonia. Clin Infect Dis 2020. doi:10.1093/cid/ciaa963. [Epub ahead of print: 10 Jul 2020].

17 Wu S, Du Z, Shen S, et al. Identification and validation of a novel clinical signature to predict the prognosis in confirmed coronavirus disease 2019 patients. Clin Infect Dis 2020;71:3154-62. doi:10.1093/cid/ciaa793

18 Liang W, Liang H, Ou L, et al. Development and validation of a clinical risk score to predict the occurrence of critical illness in hospitalized patients with COVID-19. JAMA Intern Med 2020;180:1081.

19 Yan L, Zhang H-T, Goncalves J, et al. An interpretable mortality prediction model for COVID-19 patients. Nat Mach Intell 2020;2:283-8.

20 Shang Y, Liu T, Wei Y, et al. Scoring systems for predicting mortality for severe patients with COVID-19. EClinicalMedicine 2020;24:100426.

21 Zhang S, Guo M, Duan L, et al. Development and validation of a risk factor-based system to predict short-term survival in adult hospitalized patients with COVID-19: a multicenter, retrospective, cohort study. Crit Care 2020;24:438.

22 Haimovich AD, Ravindra NG, Stoytchev S, et al. Development and validation of the quick COVID-19 severity index: a prognostic tool for early clinical decompensation. Ann Emerg Med 2020;76:442-53.

23 Moons KGM, Altman DG, Reitsma JB, et al. Transparent reporting of a multivariable prediction model for individual prognosis or diagnosis (TRIPOD): explanation and elaboration. Ann Intern Med 2015;162:W1-73.

24 Berenguer J, Ryan P, Rodríguez-Baño J, et al. Characteristics and predictors of death among 4035 consecutively hospitalized patients with COVID-19 in Spain. Clin Microbiol Infect 2020;26:1525-36

25 Borobia AM, Carcas AJ, Arnalich F, et al. A cohort of patients with COVID-19 in a major teaching hospital in Europe. J Clin Med 2020;9. doi:10.3390/jcm9061733. [Epub ahead of print: 0406 2020].

26 World Health Organization-International Severe Acute Respiratory and Emerging Infections Consortium (ISARIC). COVID-19 core case report form. acute respiratory infection clinical characterisation data tool, 2016. Available: https://media.tghn.org/ medialibrary/2020/06/ISARIC_WHO_nCoV_CORE_CRF_Modules.pdf

27 Charles PGP, Wolfe R, Whitby M, et al. SMART-COP: a tool for predicting the need for intensive respiratory or vasopressor support in community-acquired pneumonia. Clin Infect Dis 2008:47:375-84.

28 Levey AS, Stevens LA, Schmid CH, et al. A new equation to estimate glomerular filtration rate. Ann Intern Med 2009;150:604-12.

29 Riley RD, Ensor J, Snell KIE, et al. Calculating the sample size required for developing a clinical prediction model. BMJ 2020;368:m441.

30 Knight SR, Ho A, Pius R, et al. Risk stratification of patients admitted to hospital with covid-19 using the ISARIC who clinical characterisation protocol: development and validation of the 4C mortality score. BMJ 2020:370:m3339. 